\title{
Retrospective Comparison of the Occurrence and Abundance of Rusty Blackbird in the Mackenzie Valley, Northwest Territories
}

\section{Comparaison rétrospective de l'occurrence et de l'abondance du Quiscale rouilleux dans la vallée du fleuve Mackenzie, Territoires du Nord-Ouest}

\author{
$\underline{\text { Craig S. Machtans }}^{1}, \underline{\text { Steven L. Van Wilgenburg }}^{2}$, Lindsay A. Armer $^{1}{ }^{1}$, and $\underline{\text { Keith A. Hobson }}^{2}$
}

\begin{abstract}
Rusty Blackbird is listed as a species of "special concern" by the Committee On the Status of Endangered Wildlife In Canada, and has shown steep population declines in recent decades. Forty-five locations with historical survey data from the 1970s in the Mackenzie Valley, Northwest Territories, Canada were revisited in 2006 to check for changes in the occurrence or abundance of Rusty Blackbird. Our retrospective analysis revealed a number of analytical challenges for such comparisons that we describe. The number of lakes on which this species occurred does not appear to have declined significantly in the past three decades when a correction for survey duration was applied. The range-wide decline of $5.1 \% / y r$ based on Christmas Bird Count data would have resulted in 2006 occupancy at $\approx 5$ lakes. We estimate that with correction this would have increased to $\approx 26$. However, naive or unadjusted analyses with a Chi-squared test showed a significant decline. A simulated resampling of the historical data was performed using a repeatability factor of $62 \%$ that was derived from a subset of historical lakes that was visited twice in the 1970s. Only 8 of 13 lakes resurveyed had the same results on both historical visits. Our unadjusted 2006 results are a likely outcome, i.e., a $14.9 \%$ chance of finding this result, when this repeatability factor is considered, and the likelihood of no change is higher when our corrected data are considered. The possibility of double counting in the historical data further reduced the likelihood of a large decline in relative abundance. Therefore, Rusty Blackbird occurrence does not appear to have changed significantly in the past $33 \mathrm{yr}$ in the Mackenzie Valley. We conclude with a qualitative discussion that supports the notion that declines in the southern parts of their range may be a large factor in the observed rates of population decline.
\end{abstract}

RÉSUMÉ. Le Quiscale rouilleux fait partie des espèces préoccupantes selon le Comité sur la situation des espèces en péril au Canada, et ses populations ont subi un déclin marqué au cours des dernières décennies. En 2006, nous sommes retournés recenser 45 sites de la vallée du fleuve Mackenzie, Territoires du NordOuest, Canada, pour lesquels il existait des données d'inventaire datant des années 1970, afin de vérifier les changements d'occurrence et d'abondance du Quiscale rouilleux. Nous décrivons ici certains problèmes que notre analyse rétrospective a fait ressortir. Le nombre de lacs où l'espèce était présente ne semble pas avoir diminué significativement durant les trois dernières décennies lorsqu'on corrige pour tenir compte de la durée de l'inventaire. Le déclin de 5,1 \% par année dans l'ensemble de l'aire, d'après les données du Recensement des oiseaux de Noël, aurait dû se traduire par la présence de l'espèce à $\approx 5$ lacs en 2006; nous avons plutôt détecté l'espèce à 21 lacs ( $\approx 26$ avec la correction). Toutefois, des analyses sans correction au moyen d'un test de chi-carré ont montré un déclin significatif. Nous avons simulé un ré-échantillonnage des données historiques à l'aide d'un facteur de répétabilité de $62 \%$, dérivé d'un sous-échantillon de lacs qui avaient été visités à deux reprises dans les années 1970 (seulement 8 des 13 lacs montraient les mêmes résultats pour les deux visites). Nos résultats non-corrigés de 2006 sont vraisemblables (c.-à-d. qu'ils ont $14,9 \%$ de chance de se produire) lorsque l'on tient compte de ce facteur de répétabilité, tandis que la



BIRD STUDIES CANADA 
possibilité qu'il n’y ait eu aucun changement est plus élevée lorsqu'on utilise nos données corrigées. La possibilité d'un double comptage dans les données historiques réduit encore davantage la vraisemblance d'un déclin important de l'abondance relative. Ainsi, l'occurrence du Quiscale rouilleux ne semble pas avoir changé significativement au cours des 33 dernières années dans la vallée du fleuve Mackenzie. Nous concluons avec une discussion qualitative qui soutient l'idée que les déclins dans le sud de l'aire de répartition pourraient constituer un élément important dans les déclins de population rapportés.

Key Words: COSEWIC; Euphagus carolinus; Mackenzie Valley; population change; Rusty Blackbird; species at risk.

\section{INTRODUCTION}

Rusty Blackbird (Euphagus carolinus), once a common wetland-associated breeding species throughout the boreal forest of North America, has declined precipitously in recent decades. These declines were summarized by Greenberg and Droege (1999) using a large number of mostly qualitative sources to indicate that Rusty Blackbird populations have been declining for at least the last century. The recently accelerating declines evident in Breeding Bird Survey (BBS) and Christmas Bird Count (CBC) data were also highlighted by Greenberg and Droege (1999). The most recent BBS trend analyses (Sauer et al. 2005) show a $12.8 \%$ annual, statistically significant decline in Canada (1966-2005), with the caution that low relative abundance may be influencing the results. A recent CBC data analysis (1965-1966 to 2002-2003, Niven et al. 2004) showed a $5.1 \%$ statistically significant annual decline across the entire winter range of the Rusty Blackbird. These data are likely more reliable than BBS data for trend analysis of this species (Niven et al. 2004), given the relatively large area of the wintering ground covered by CBC surveys compared to the small area of the breeding grounds covered by BBS routes (see dashed line in Fig. 1). Several other sources of data show statistically significant declines (summarized in COSEWIC 2006), including the étude des populations d'oiseaux du Québec (-2.7\%/yr from 1970-2003), the Mackenzie Nature Observatory (banding station, -24.3\%/yr 1996-2002), and the Ontario Breeding Bird Atlas. The last reference indicates a $12 \%$ and $4 \%$ decline in northern and southern survey squares, respectively, with Rusty Blackbirds from 1981-1985 period to 2001-2005 period.
The Canadian population of this species is currently estimated at 110,400 to $2 \times 10^{6}$ birds (COSEWIC 2006). The estimated decline according to the CBC or the BBS indicates that there are about $10 \times 10^{6}$ fewer Rusty Blackbirds than historic levels. Rusty Blackbird was listed as "special concern" by the Committee On the Status of Endangered Wildlife In Canada (COSEWIC) in 2006, in part due to estimated trends and due to the paucity of data on the species. The species is pending scheduling on Canada's Species At Risk Act.

Causes of the steep population decline are far from apparent. A recently formed International Rusty Blackbird Technical Group produced a research agenda that hypothesized the most likely reasons for the bird's decline (IRBTG 2005). The potential causes include a variety of direct and indirect habitat alterations (breeding and wintering), chronic toxicity, and direct kills on the wintering ground (IRBTG 2005).

One basic way of focusing the IRBTG research effort is to understand if the declines on the breeding ground are widespread or local. Most of the breeding range for the species is north of the effective limit for the BBS (Fig. 1). A significant part of the range of Rusty Blackbird lies in the Northwest Territories, Canada, an area where historic survey data exist. Specifically, surveys associated with a proposed pipeline project through the Mackenzie Valley during the 1970 s could provide a reference point for current population estimates. However, using this historical data for comparisons presents a set of problems that is likely common to many historical datasets: abundance data are incomplete, estimates of detectability are difficult or impossible to reconstruct, and exactly repeating the historical surveys would be prohibitively expensive. 
Fig. 1. Study area is shown in the black rectangle and inset, breeding range of the Rusty Blackbird in Canada is shown in gray shading after COSEWIC (2006), and location of 45 lakes visited within the Mackenzie Valley, NT are the black triangles for this study. The dashed line on the Canada-wide map represents the northern limit of valid analyses from the Breeding Bird Survey (from Sauer et al. 2005).

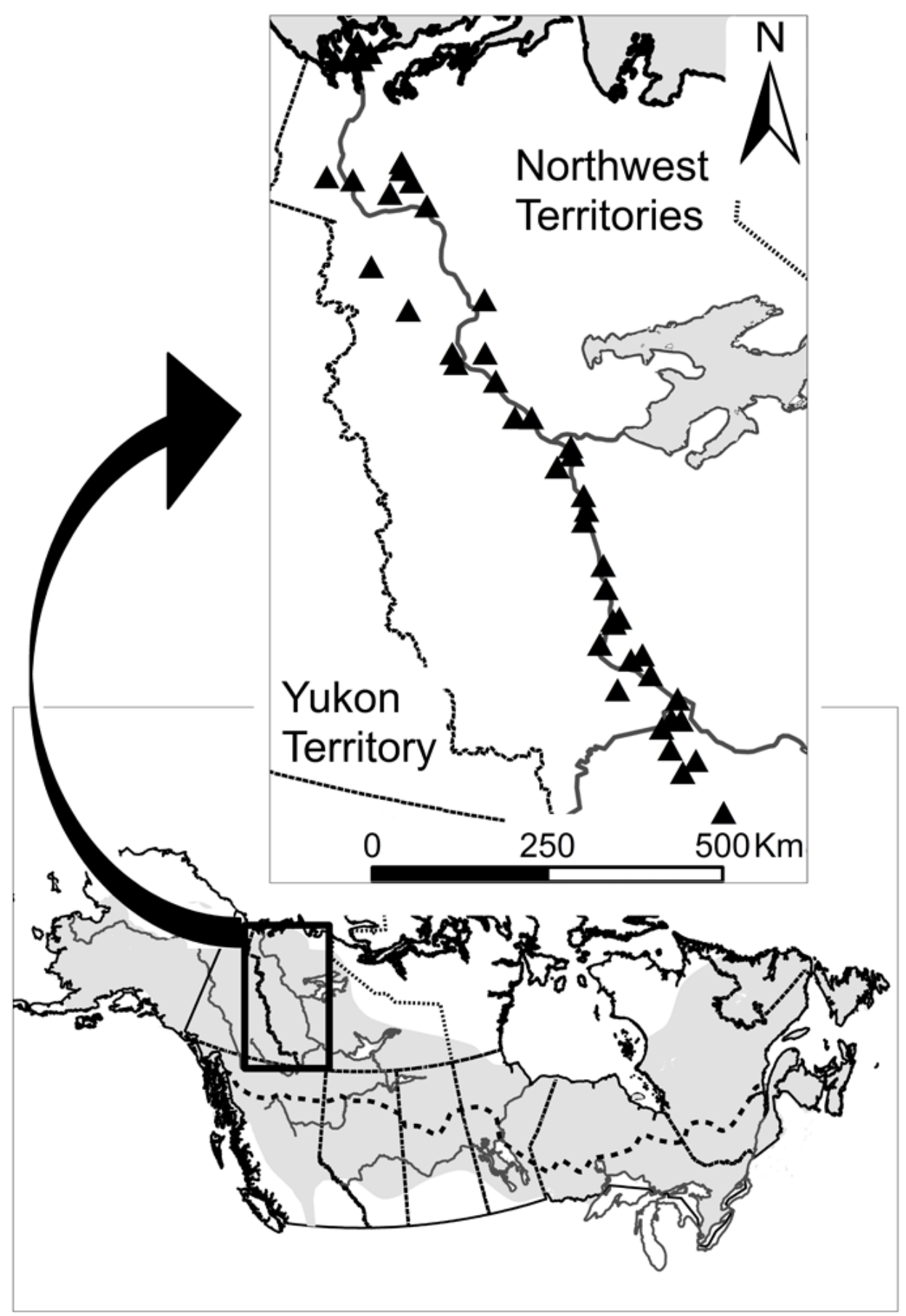


Repeating the surveys would also be somewhat counterproductive since the original efforts were not targeting Rusty Blackbirds in particular.

Some historical data are better than none, even with these problems. The challenge for managers and researchers is to maximize the value of the data at hand to help inform the conservation issue as was done by Greenberg and Droege (1999). We examine methods for dealing with the uncertainty inherent in such retrospective analyses. Therefore, the objective of this study was to determine if the occurrence and relative abundance of Rusty Blackbirds in the Mackenzie Valley has changed between the mid-1970s and 2006, acknowledging complications with direct comparisons of data. Assuming local population numbers are in part determined by range wide factors, our hypothesis was that the number of birds observed in 2006 would be a fraction of the 1970 s totals, as calculated by the CBC range-wide annual decline of $5.1 \%$ over the past 33 yr. Alternatively, decline or lack thereof would be due to regionally specific factors on the breeding grounds.

\section{METHODS}

\section{Historic data collection}

Ground surveys for all species of birds, including Rusty Blackbird, were conducted from 1971 to 1975 as part of the environmental review for a proposed pipeline through the Mackenzie Valley (Schweinsburg 1974, Salter and Davis 1974, Tull et al. 1974, Ward 1975, Patterson et al. 1977, Wiseley and Tull 1977). Study sites were adjacent to 61 lakes that were large enough to land on in a small airplane with floats, typically $>1 \mathrm{~km}$ across. The southern-most lake was near the Alberta border at $60.4333^{\circ} \mathrm{N}$ and $119.6500^{\circ}$ $\mathrm{W}$, whereas the northernmost lake was in the Mackenzie Delta at $69.2833^{\circ} \mathrm{N}$ and $134.9139^{\circ} \mathrm{W}$ (Fig. 1).

Transect surveys at or near each lake were conducted by two pairs of observers, with each pair surveying one transect at a time. Total transect length at each lake varied between $3370 \mathrm{~m}$ and $21,043 \mathrm{~m}$, averaging $7332 \mathrm{~m} \pm 3003 \mathrm{~m}$ (SD). Many transects were rectangular in design, finishing at the starting point. The consultant reports contained detailed hand-drawn maps for most of the lakes and of the location of transects relative to the water bodies. Surveys were conducted between 31 May and 6 July in any given year, between 0400 and 1100 , with some counts completed mid-afternoon. Observations were recorded on transect, i.e., width of $18.3 \mathrm{~m}$ or 20 yards, off transect, or incidentally, i.e., not seen during the official survey, except as noted below. No record of which individual transect the birds were recorded on currently exists, but exact lengths of each habitat sampled are listed in the printed volumes. Certain volumes recorded exact survey effort (1974 and 1975), whereas the earlier volumes only reported general start and finish times for a typical day. Thirteen lakes were visited in two separate years, and four lakes were visited twice in one year.

Abundance data, including notations for on- and offtransect and incidental observations were printed in the historical reports for 1971, 1972, and 1973 survey data. For lakes surveyed in 1974 and 1975, these data were not printed in the reports and, after a thorough search by original authors, it was apparent that the only known copies of these appendices no longer exist. On-transect numbers could be back-calculated from density calculations in their text in only a few instances.

\section{6 data collection}

It would have been logistically impossible to visit 45 lakes and duplicate the effort from the 1970s, yet still complete the project in one year. We therefore optimized our sampling since the original historical transects were not placed specifically to find Rusty Blackbirds but to sample a range of the vegetation types present in the Mackenzie Valley. We allocated our effort only to the habitats most likely to contain Rusty Blackbirds, based on both our own personal experience and the prevalent habitat type in which the birds were located during the historical surveys. For example, in Appendix 4 of Ward [1974], 74\% of birds were found in black spruce muskeg. Likely habitats were shorelines of the main survey lakes, any nearby smaller water bodies that were near historical transects, and wetlands and muskeg habitats in between; essentially areas with standing water and muskeg or bog habitat (Fig. 2). Within this framework, the portions of the areas sampled corresponded to the same locations of the historical transects. Thirteen of the 45 lakes we revisited have had their surrounding forests burned in the time between historical and modern surveys. 
Forty-five of the 61 historical survey sites were revisited 1-23 June, 2006. The 16 lakes not surveyed included 4 that were too shallow for landing in the central Mackenzie Valley, and 12 others in the Mackenzie Delta that had no historical records of Rusty Blackbird and were not surveyed to manage air charter costs. Two observers were used at each lake. Several approaches were used based on the type of lake and potential suitability of nearby habitats for Rusty Blackbirds. If most suitable habitat and the historical transects paralleled the lake, a canoe was used to survey a shoreline transect using two observers together, or shoreline transects were walked with the two observers apart. Walking transects were done in separate areas to maximize area covered. If the transects were perpendicular to the main lake, ones with suitable habitat were surveyed, thereby considerably increasing the sample of individual wetlands surveyed. Finally, if the floatplane could not get to the shoreline for safety reasons, stationary surveys, i.e., point counts and searches, were conducted in a few locations around the lake. Rusty Blackbirds were recorded on transects or point counts of unlimited width with notation of aural or visual observation and sex and behavior were recorded if ascertained. Total search time and distance for each transect was recorded. All reasonable efforts were made to reduce doublecounting of individuals, with more detail provided in the Discussion.

Of the 45 lakes we visited, 19 were only surveyed in 1974 or 1975 and therefore abundance data are not available as noted above. Fourteen had presence noted in the historical reports as on, off, or incidental to transect, so for these lakes we do not know the total number of Rusty Blackbirds observed. We were able to determine on-transect abundance for three lakes, leaving eleven lakes where only presence or absence data were available. Presence, in these cases, would also have included birds seen on, off or incidental to transect surveys.

\section{Statistical analysis}

Analyses were conducted to compare patterns of occurrence, i.e., presence or absence, and patterns of abundance. Analyses of occurrence used a Chisquared test, with two expected ratios. The first ratio of 30 of 45 lakes with Rusty Blackbirds represented the result from all lakes surveyed once and the first visit of lakes surveyed twice. The second ratio of
31 occupied of 45 lakes was from all lakes surveyed once and the second visit of lakes surveyed twice.

Recent literature highlights the importance of detection probability in making valid comparisons in presence/absence surveys (e.g. Thompson 2002, MacKenzie et al. 2003, Bart et al. 2004, McCallum 2005). Due to logistical constraints and the nature of the historic data, we were unable to generate standard estimates of detection probability. Therefore, we did three things to account for differential survey effort. First, we calculated the expected fraction of all birds that we actually encountered on our surveys. Second, we used the time to our first observations at each lake to estimate how much effort would have been required before no new observations would have been expected at lakes where we found no birds with our search effort, i.e., our "discovery rate". The calculation was made by integrating the function describing the discovery rate. This allowed us to adjust our data for search times that were lower than in the historical data. Third, we used the rate of accumulation of total individuals to calculate a theoretical maximum number of individuals for our surveys. We also calculated the maximum number occurring when our discovery rate reached zero.

We also used an approach incorporating an expectation of between-year variation to compare the historical and contemporary data. We derived an estimate of how occupancy varied between years in the historical data from a subset of lakes that were visited twice historically with the same methods and effort. We used that value to calculate the probabilities of all possible occupancy ratios on a random visit to the same subset of lakes, which we termed repeatability. We defined repeatability as the proportion of the subsample where the encounter history was the same, i.e., present in both visits or absent in both visits. Eight of 13 lakes (62\%) had the same results between the two historical visits. We then ran a simulation in Microsoft Excel 2003, generating 10,000 presence-absence values derived from the historical dataset, using a repeatability rate of $62 \%$. Each simulation run held a random sample of 28 lakes (62\% of 45) static, and changed the remaining 17 lakes from presence to absence or vice versa mimicking the results of the historical resurvey. This allowed us to estimate the probability of obtaining the observed presence/absence ratios given the estimated rate of repeatability. Although this approach does not directly account for detectability, our repeatability estimate reflects the 
Fig. 2. Typical wetland complex composed primarily of black spruce muskeg in which Rusty Blackbirds were detected; insets depict typical shoreline attributes of occupied sites. Photo credits: main image, CSM; inset habitats, KAH; Rusty Blackbird, S. Denault.

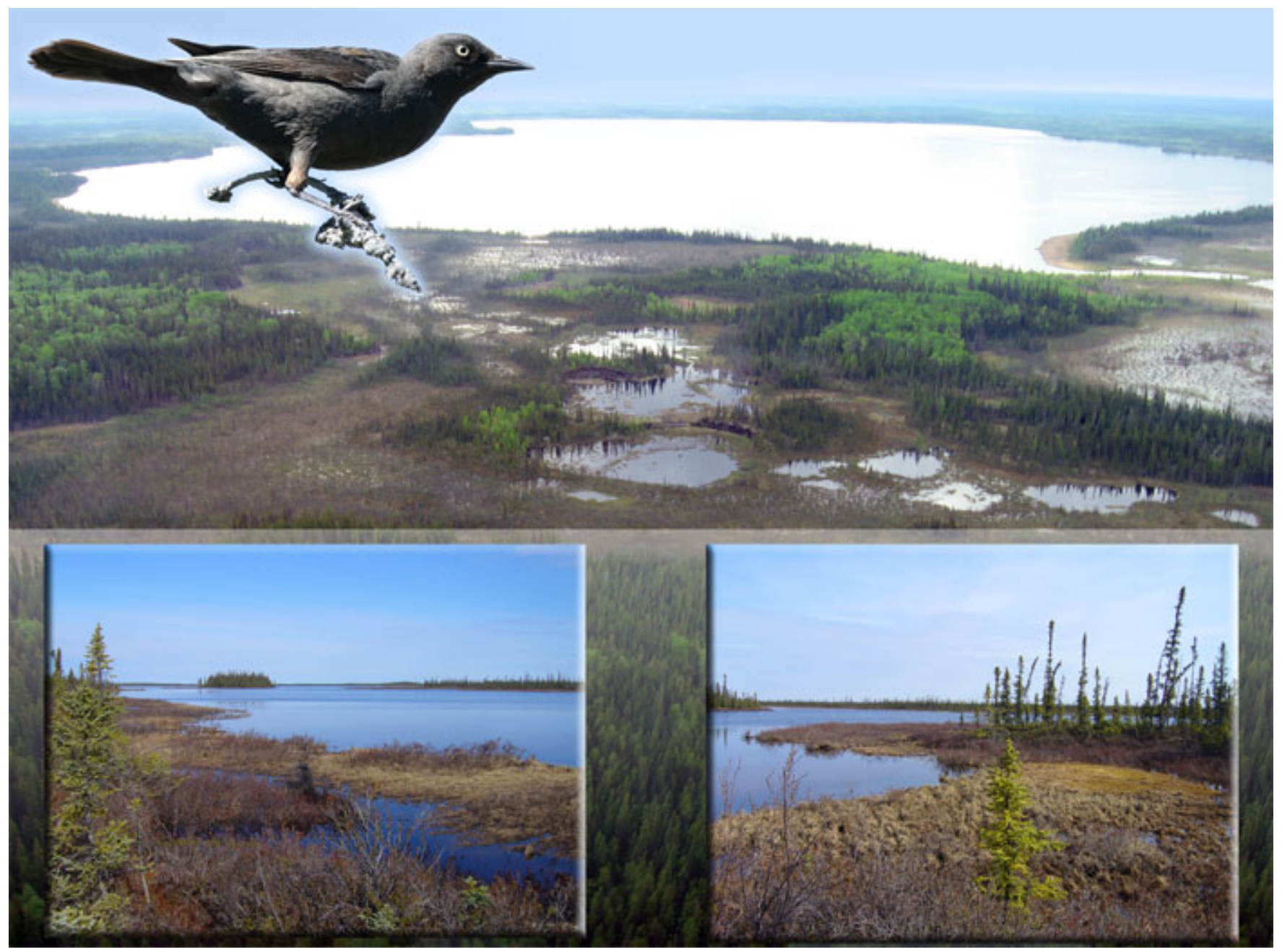

detection, survival, extinction and colonization probabilities over a short duration, i.e., $2 \mathrm{yr}$, and therefore allows some measure of how likely our results would be if the surveys were repeated again under similar conditions.

Patterns in abundance were compared using rescaled values to avoid undue influence of potential double counting. Abundance at each lake in both surveys was rescaled into four classes $(0=0,1=1$, $2-5$ birds $=2, \geq 5$ birds $=3$ ). We considered our study a repeated-measures analysis, so a two-tailed
Wilcoxon-Signed Ranks test was used to compare the data. Because abundance data were not available for 14 lakes in the historical dataset, the results from the modern surveys were scored as one when $\geq 1$ bird was recorded resulting in a tied rank. More complex methods such as multinomial regression were investigated to account for habitat changes from burns, and differential effort as measured by time and distance, but were abandoned. The second order Akaike information criteria $\left(\mathrm{AIC}_{\mathrm{c}}\right)$ criteria showed that the covariates just mentioned were not adding any useful information to the models. 
Results for the historical data and comparisons between 2006 and the historical data are based only on the 45 lakes visited then and now. Statistics were computed in SPSS 13.0, curve fitting in SigmaPlot 8.0, and algebra and calculus in Excel 2003. Standard error is reported unless otherwise noted.

\section{RESULTS}

Presence-absence, abundance measures, and survey parameters are summarized in Table 1 for both the historic and current survey periods. The number of blackbirds detected in 2006 was not directly related to search hours or the length of transects through habitats in which we expected the birds (linear regressions, $\mathrm{F}_{[1,43]}=0.068$ and $1.517, P=0.78$ and 0.23 respectively, $R^{2}<0.03$ in both cases). Other polynomial curves fit the data as poorly. The lack of a relationship between effort and abundance was similar for the historical data where exact search time was known $\left(F_{[1,17]}=0.523, P=0.48\right)$ or for distance surveyed through habitats where Rusty Blackbirds could be expected $\left(F_{[1,43]}=1.06, P=\right.$ 0.31 ).

\section{Detectability corrections: occupancy and abundance}

Rusty Blackbirds were relatively conspicuous, a likely reason why there were poor relationships between effort and count numbers noted above. The mean time to detect the first Rusty Blackbird at any lake with observations was $27.5 \mathrm{~min}$ (29.6 SD), with a median time of $12.5 \mathrm{~min}$. The first observation was usually visual, or both visual and aural. The average time to detection for all observations was 34.2 min (27.7 SD). Figure 3 summarizes the relationship between time spent surveying, the cumulative number of birds observed through time, and how long it took to observe the first bird at each lake. A 4 hr recording made at one site where Rusty Blackbirds were quickly visually detected indicates that an aural survey would have to be at least $40 \mathrm{~min}$ long to detect the birds in any random period of the recording. The longest observation time taken to observe the first Rusty Blackbird at any lake (96 min) was captured aurally on a recording once a visual survey had been completed and observers left.
We derived a correction for our occupancy estimate using an inverse, third order polynomial curve approximating the decline for our discovery rate (thin line in Fig. 3). The best-fit equation describing this relationship was $\mathrm{y}=y_{o}+a \mathrm{x}^{-1}+b \mathrm{x}^{-2}+c \mathrm{x}^{-3}$ with $R^{2}=0.93$. The parameters were $y_{0}=-1.806, a=$ $502.7, b=-6328$, and $c=35820$. Taking the integral of the curve equation for the actual observation times (10 to 100 minute bins) and comparing that to the total area under the curve from 10 minutes to when $\mathrm{y}=0$ indicates we likely found $0.796(80 \%)$ of all potential observations. Solving for $\mathrm{y}=0$ gives an approximation of how long a survey would have had to have been to rule out the presence of a Rusty Blackbird. Given $y=0$, any birds present should be detected within 265 min, which is less than the historical minimum of approximately 270 and an average of $336 \mathrm{~min} /$ site of search time (Table 1). Therefore, if the shape of the curve for the discovery rate was similar between 2006 and the historic surveys, all surveys in the 1970's should have accurate estimates of presence/absence since detectability should have been $\approx 1$.

We derived a correction for our estimate of abundance by fitting an exponential growth curve to the number of individuals accumulating through time (thick line in Fig. 3). The best-fit equation describing this relationship was $\mathrm{y}=y_{0}+a\left(1-e^{-b} \mathrm{x}\right)$ with $R^{2}=0.995$. The parameters were $y_{o}=-1.852$, $a=85.51$, and $b=0.02112$. This equation is maximized $\left(\lim _{\mathrm{x}-\infty}\right)$ at $y_{o}+a$, or 83.7 individuals. Since we observed 74 birds, the correction is $1-((83.7-74) / 83.7)=0.88$. The correction factor when the expected discovery rate was zero was nearly identical, as $\mathrm{y}=83.3$ when $\mathrm{x}=265 \mathrm{~min}$.

\section{Range-wide decline hypothesis}

Using the $5.1 \%$ annual rate of decline for Rusty Blackbird indicted by the CBC data, the 90 birds observed in historical surveys (Table 1) would have been reduced to 16 , as calculated by $(90 \times(1-d)$ $Y$ ), where $d$ is the rate of decline and $Y$ is the number of years between observations, i.e., 33 in this case. We observed 40 individuals at the same subset of lakes where abundance was directly comparable, equivalent to a $2.4 \%$ annual decline. If we correct our abundance estimates by the factor derived above (40/0.88), our expected total abundance would be 45 , equivalent to a $2.1 \%$ annual rate of decline, but see the Discussion for concerns about double 
Table 1. Comparison of historical and modern data for Rusty Blackbirds at 45 lakes visited in the 1970s and in 2006 in the Mackenzie Valley, NT, Canada. Thirteen lakes were visited twice in the 1970s, so two presence absence ratios are presented for the historical data. SE is presented for means.

\begin{tabular}{lcc}
\hline \hline Descriptor & $\begin{array}{c}\text { Historical Value } \\
(1970 \mathrm{~s})\end{array}$ \\
(2006)
\end{tabular}

Presence : Absence ratio

All 45 lakes, first visit data

$\begin{array}{lc}30: 15 & 21: 24 \\ 31: 14 & \text { n/a } \\ 8 \text { of } 13 & \text { n/a } \\ (62 \%) & \end{array}$

All 45 lakes, second visit data

$(62 \%)$

Lakes surveyed twice in 1970 s with same results ${ }^{\dagger}$

Maximum individuals at any lake

90

40

Mean abundance

$3.5 \pm 1.0$

$1.5 \pm 0.6$

Number of lakes with $>5$ birds

2

Total survey time $(\mathrm{h})^{\S}$

Including general estimate

$6.6 \pm 0.2$

$\mathrm{n} / \mathrm{a}$

Including only exact times ${ }^{\S}$

$5.6 \pm 0.2$

$1.9 \pm 0.1$

Transect length (m)

Through expected habitat

$2443 \pm 297$

$1570 \pm 138$

Through all habitats

$7499 \pm 470$

$\mathrm{n} / \mathrm{a}$

${ }^{\dagger}$ Same result is defined as either present in both years or absent in both years.

$¥$ Only presented for sample of lakes $(n=26)$ when total historical abundance is available. Statistical analyses used $n=45$ lakes, but recoded the modern data to presence/absence only for the paired lakes in the historical data. Seventy-four Rusty Blackbirds were observed in 2006.

${ }^{\S}$ Historical data $n=19$ lakes, modern data $n=45$ lakes. Total time for modern data is person-hours, so two people searching in independent areas for $1 \mathrm{~h}$ was tallied as $2 \mathrm{~h}$. Historical surveys used two observers, but on the same transect simultaneously < $20 \mathrm{~m}$ apart. For detecting Rusty Blackbirds, it was assumed this was one effective observer.

IExpected habitat was classified based on the notes in the historical volumes and included four habitat classes, all various types of bog or fen (nos. 50, 99, 100, 226). Modern transects and counts were only done in expected habitats. 
Fig. 3. Time to the first detection of Rusty Blackbirds at each lake is represented by bars compared to both the total number of observations over time and the cumulative percent of observations. Bars are at the end of the time interval, so the first bar is the 0-10 min interval, then 10-20 min, etc. Half of all birds observed were seen within $30 \mathrm{~min}$ from the start of a survey. The longest time to detect the first bird at a lake was $96 \mathrm{~min}$. The best fit line for declining discovery rate had $R^{2}=0.93$ and had $y=0$, i.e., no birds expected, at $265 \mathrm{~min}$. The best fit line for accumulation rate had $R^{2}=0.995$ and reached a maximum value of 83.7 birds. Equations and constants are provided in the text.

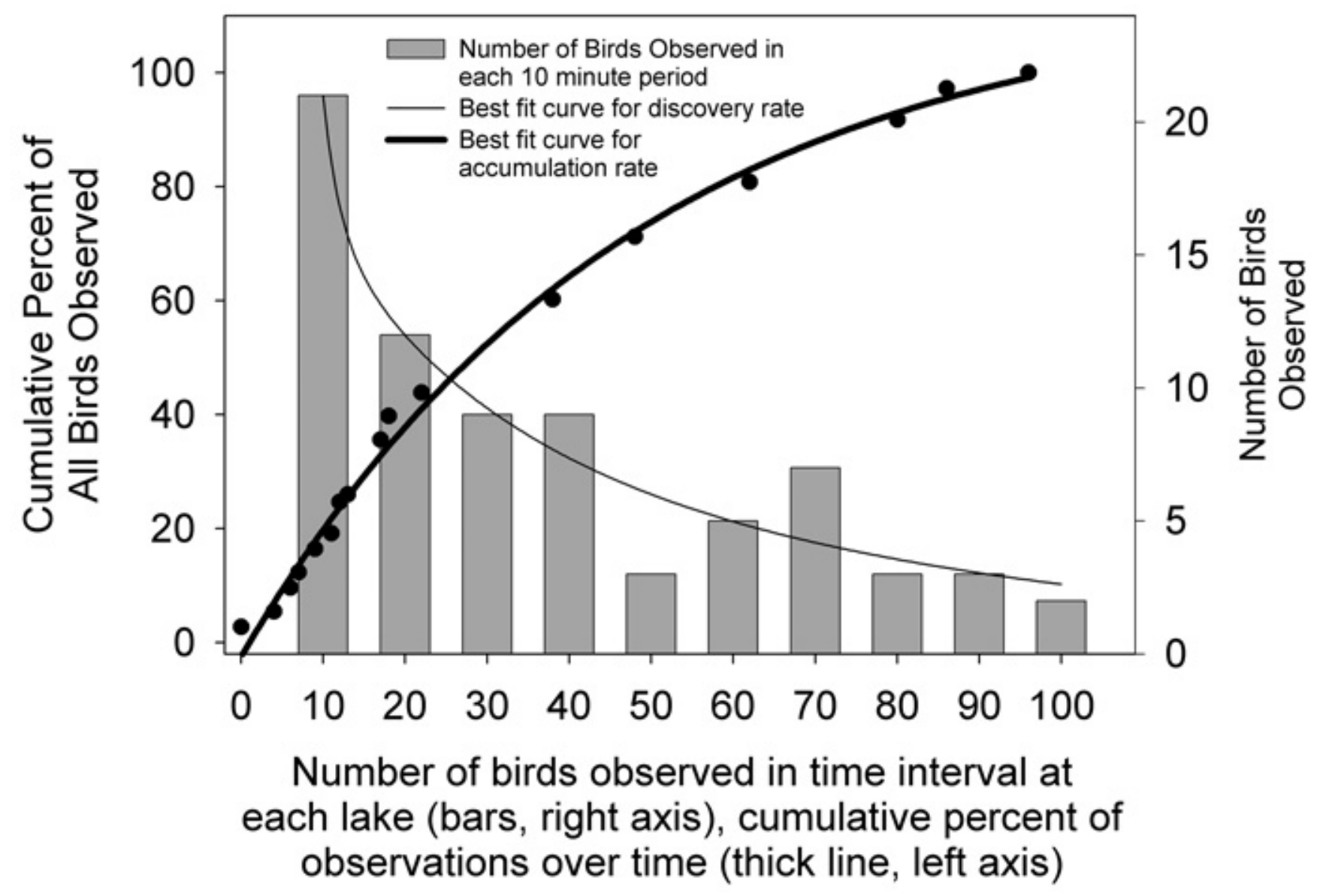


counting in the historical data. If occupancy, i.e., presence/absence data only, were declining at the same $\mathrm{CBC}$ rate as the population, we should have only found birds at 5 or 6 lakes of the original 30 . Instead, we found birds at 21 lakes. Applying the correction derived from our polynomial curve (0.80), our corrected occupancy estimate would be $\approx 26$ lakes.

\section{Patterns of occurrence}

Using uncorrected data, significantly fewer lakes had Rusty Blackbirds in 2006 compared to historical occurrence $\left(\chi^{2}{ }_{[1]}=8.10, P=0.004\right.$ for first visit comparisons, $\chi^{2}{ }_{[1]}=10.37, P=0.001$ for second visit comparison). Eliminating all the lakes where major habitat change occurred, e.g., forest fires, the presence-absence ratios were 23:9 historically and 16:16 currently, repeating the same statistical pattern of occupancy change $\left(\chi^{2}{ }_{[1]}=7.58, P=0.006\right)$ when all 45 lakes were analyzed without regard to major habitat change. If the occupancy estimate for 2006 is adjusted using our correction to 26 lakes there would be no statistical difference from historical ratios $\left(\chi^{2}{ }_{[1]}=1.60, P=0.21\right)$

For the simulations run on the historical data, there are only 16 possible presence-absence ratios when the data are resampled with repeatability of $62 \%$. The number of possible ratios was calculated as $[(30-x)+(17-x)]$ where $x$ was the number of presences in the lakes not kept identical. With occupancy at 28 lakes kept identical, $x$ ranged from 2 to 17 . The resulting ratios ranged from a low of 13:32 to a high of $43: 2$. The solution only allows odd numbers for presence. The chance of finding each of the possible ratios is summarized in Table 2 .

The Excel simulation results showed that Chisquared values of 8.10 or 10.37 , i.e., our data vs. the historical results from above, falls within the $95 \%$ confidence interval of the simulated data (mean 4.17, SD 3.72; $95 \% \mathrm{CI}$ of data [not CI of mean] is -3.12 to 11.46 ). More precisely, Table 2 shows that the chance of finding our result of 21:24 is 0.148 . That value is one of the four most likely outcomes in which only $62 \%$ of sites are expected to remain the same. The number of lakes occupied using the corrected data would change our ratio to $26: 19$, and Table 2 values indicate that this ratio is again quite likely given the expectation of $62 \%$ repeatability of surveys.

\section{Patterns of abundance}

The data, with abundance coded into the classes noted above and with abundance adjustments as detailed in the Methods section, showed only a weak decline in Rusty Blackbird abundance, i.e., 19 ranks lower in modern data, 8 ranks higher in modern data, 18 ties, $Z=-1.70, P=0.090$. The result was statistically stronger when the non-categorized data, i.e., actual abundance or presence, were used. That analysis resulted in 21 ranks lower in modern data, 8 ranks higher in modern data, and 16 ties, $Z=-2.01$, $P=0.036$, but see the Discussion for our concern with respect to double-counting in the historical data.

\section{DISCUSSION}

Urgent conservation problems often result in a compromise: imperfect but adequate data gathered quickly is often more useful than higher quality data that requires a large time and financial investment. The decline of the Rusty Blackbird is one of those urgent problems. Quantitative data from its breeding grounds are scarce, and time-series data are almost nonexistent. That deficiency makes it difficult to determine something as simple as if declines are range wide or region specific. Without that basic knowledge, it is difficult to prioritize areas for research into the causes of the decline.

Our retrospective comparison indicates that Rusty Blackbird occurrence has probably changed very little in the past $33 \mathrm{yr}$ in the Mackenzie Valley, and certainly not as much as would be predicted by a range-wide decline of the magnitude indicated by the CBC data. Once differential survey effort was accounted for, there was likely little change in occurrence as calculated by either a simple Chisquared test or the more complex analysis that considered the likelihood of results of repeated surveys with high effort. More complex analyses considering abundance and covariates were, at best, of questionable merit when all the problems of the two datasets were considered.

It is worth noting that the naive test of occurrence, i.e., without accounting for detectability, would have indicated that there was a significant change in occupancy of lakes by Rusty Blackbirds in the past three decades. It has become unacceptable to rely on unadjusted counts as a means of comparing change, and detectability should be considered 
Table 2. Possible presence-absence ratios and their chances of being drawn from an initial case, i.e., historical value, of $30: 15$ when a $62 \%$ repeatability ratio is assumed for re-surveys. Probabilities calculated in Microsoft Excel 2002 using HYPGEOMDIST $(((47-\mathrm{x}) / 2), 17,30,45)$ where $x$ ranges from 13 to 43 based on calculations in the text.

\begin{tabular}{cc}
\hline \hline Possible presence-absence ratios & Chance of drawing this ratio \\
\hline $13: 32$ & 0.00011 \\
$15: 30$ & 0.00198 \\
$17: 28$ & 0.01477 \\
$19: 26$ & 0.05998 \\
$21: 24$ & 0.14820 \\
$23: 22$ & 0.23547 \\
$25: 20$ & 0.24786 \\
$27: 18$ & 0.17527 \\
$29: 16$ & 0.08346 \\
$31: 14$ & 0.02655 \\
$33: 12$ & 0.00554 \\
$35: 10$ & 0.00073 \\
$37: 8$ & 0.00006 \\
$39: 6$ & $2.6 \times 10^{-6}$ \\
$41: 4$ & $5.5 \times 10^{-8}$ \\
$43: 2$ & $3.9 \times 10^{-10}$ \\
& \\
\hline
\end{tabular}

before a conclusion is reached (e.g. Thompson 2002, MacKenzie et al. 2003, McCallum 2005). Our naive test would have gone from highly to only marginally significant $(P=0.058)$ if we saw birds at only three additional lakes, and nonsignificant $(P$ $=0.11$ ) with observations at four additional lakes. This should serve as a strong caution that correction factors are important for other retrospective analyses where exact survey methods cannot be duplicated. These analyses also reveal the need for large sample sizes in such comparisons in order to increase power of statistical inference. At minimum, we suggest that any retrospective analyses at least perform sensitivity analysis using various values of detectability.

Another complicating factor in making the comparison between the historical and contemporary data is double counting. We found that Rusty Blackbirds ranged widely at any given lake. Birds were often observed moving along a lakeshore, or traveling across large expanses of forest or water between nests and foraging areas. Our approach in 2006 with relatively more focused search times in likely habitats, made it easier to avoid double counting. This would have been more difficult or 
impossible in the historical surveys. There, single, continuous transects were often several kilometers long, in rectangular shapes that ended at the starting point. They took several hours to complete, and observations at the beginning of a transect would be difficult to identify as different from observations a few hundred meters away as the transect was finished several hours later. Given that we commonly saw flights on the order of several hundred meters, double counting in the historical data seems likely. This again reduces our confidence that there have been any large declines in Rusty Blackbird abundance between survey periods.

Our attempt to quickly gather data for a retrospective comparison highlights some considerations for future surveys on the breeding grounds. Our results show that at most lakes where Rusty Blackbirds are present, they are visually and aurally relatively conspicuous. The median time to our first observation was only about $13 \mathrm{~min}$. In some cases, it took much longer to observe birds (Fig. 3), and the historical repeat surveys, even with ample search effort, found high interannual variability in occupancy. These three events lead to considerations for survey effort. First, Rusty Blackbirds appear to have at least two levels of conspicuousness. The first is where they are active within a relatively small area. Surveys coinciding with that active area rapidly discover the birds. Second, the birds also cover large, extended areas. Survey effort that is not coincident with use of the smaller, active areas must involve searches large enough, and for long enough, to encounter birds on their extended trips. Third, the inter-annual variation could mean that available habitat is not saturated and population levels are not high. Alternatively, if philopatry in Rusty Blackbirds follows the pattern typical of many passerines, then breeding pairs that were unsuccessful would have a high probability of dispersing to a new site for their next breeding attempt [Greenwood and Harvey 1982]. The unsuccessful pairs and floaters would appear and disappear at lakes in some random pattern. Therefore, repeat surveys at spot locations each year may not be sufficient to describe changes in the populations, and a transect approach that covers large areas may be preferable.

How do our results inform the larger conservation issue? If Rusty Blackbirds in the $130,000 \mathrm{~km}^{2}$ area of the Mackenzie Valley that we studied have not declined as much as the CBC predicted, the species must be declining more in other parts of their range to be showing the range-wide trends observed to date. This is consistent with several quantitative and qualitative observations.

First, BBS data, which are from the southern part of the species range, indicate much larger declines than the CBC data set. Second, anecdotal evidence from the southern boreal of eastern and western Canada indicates that Rusty Blackbirds have disappeared from large regions of their former breeding range (KAH and A. Smith, personal observation) and recent surveys of wetlands in the western boreal forest seem to confirm this: only 14 of 937 intensively surveyed wetlands in the Boreal Plains from western Manitoba west to north-central Alberta were occupied by Rusty Blackbird (J. Morissette, personal communication).

Third, other sources of trend data discussed in our introduction show disparate rates of decline across Canada rather than a more uniform result. The catchment area for Rusty Blackbirds for the migration monitoring stations with trends for the species have not been identified, so it is difficult to determine the regional scope of their results. However, if the decline was range-wide, there should be closer concordance between the various rates of decline in the various valid sources of trend data.

It would be very informative to complete retrospective evaluations like ours in other parts of the range of the Rusty Blackbird to confirm if declines are most evident in southern and eastern parts of the species' range. The work by DesGranges and Houde (1989) would be an ideal study to redo in the eastern portion of the species range, as they had a large sample of lakes with Rusty Blackbird and collected habitat data, including water chemistry. As noted above, new retrospective studies must carefully consider issues of detectability when comparing current and historic data.

Another potentially fruitful area of future research is the use of "forensic" comparison of feather stable hydrogen isotope ratios $(\delta \mathrm{D})$ between historic, i.e., museum specimen, and current wintering ground samples (Hobson 2005, Bowen et al. 2005). If breeding populations in the southern and eastern portions of the species range have experienced the greatest declines, the isotopic makeup of wintering ground feather samples should suggest a significantly greater proportion of the current 
sample being made up of birds that grew their feathers in the northwestern portion of their range (but see Hobson et al. 2006) than in the museum specimens. Together, retrospective surveys that are corrected for detectability along with wildlife forensic approaches may be the most fruitful approaches to examining declines in species like Rusty Blackbird that occur in remote areas.

Responses to this article can be read online at: http://www.ace-eco.org/vol2/iss 1/art3/responses/

\section{Acknowledgments:}

Thanks to Alicia Korpach (Ducks Unlimited Canada) for assisting with field surveys and to Byron Schmuland (University of Alberta) for explaining and calculating the hypergeometric probability distributions. Two anonymous reviews and the editors provided insightful comments to improve this manuscript. Funding for this study was provided by Environment Canada.

\section{LITERATURE CITED}

Bart, J., S. Droege, P. Geissler, B. Peterjohn, and C. J. Ralph. 2004. Density estimation in wildlife surveys. Wildlife Society Bulletin 32:1242-1247.

Bowen G. J., L. I. Wassenaar, and K. A. Hobson. 2005. Global application of stable hydrogen and oxygen isotopes to wildlife forensics. Oecologia 143:337-348.

COSEWIC. 2006. COSEWIC assessment and status report on the Rusty Blackbird (Euphagus carolinus) in Canada. Committee on the Status of Endangered Wildlife in Canada. Ottawa, Ontario, Canada. Available online at: URL: http://www.sara registry.gc.ca/status/showDocument e.cfm?id=1005

DesGranges, J. -L., and B. Houde. 1989. Effects of acidity and other environmental parameters on the distribution of lacustrine birds in Quebec. Pages 7-41 in J. -L. DeGranges, editor. Studies on the effects of acidification on aquatic wildlife in Canada: lacustrine birds and their habitats in
Quebec. Canadian Wildlife Service Occasional Paper No. 67. Environment Canada, Ottawa, Ontario, Canada.

Greenberg, R., and S. Droege. 1999. On the decline of the Rusty Blackbird and the use of ornithological literature to document long-term population trends. Conservation Biology 13:553-559.

Greenwood, P. J., and P. H. Harvey. 1982. The natal and breeding dispersal of birds. Annual Review of Ecology and Systematics 13:1-21.

Hobson, K. A. 2005. Stable isotopes and the determination of avian migratory connectivity and seasonal interactions. Auk 122:1037-1048.

Hobson, K. A., S. Van Wilgenburg, L. I. Wassenaar, H. Hands, W. Johnson, M. O'Melia, and P. Taylor. 2006. Using stable-hydrogen isotopes to delineate origins of Sandhill Cranes harvested in the Central Flyway of North America. Waterbirds 29:137-147.

International Rusty Blackbird Technical Group (IRBTG). 2005. Understanding the declines in the Rusty Blackbird (Euphagus carolinus): an indicator of wooded wetland health. Available online at: URL: http://nationalzoo.si.edu/ConservationAndScience/ MigratoryBirds/Research/Rusty Blackbird/.

McCallum, D. A. 2005. A conceptual guide to detection probability for point counts and other count-based survey methods. Pages 754-761 in C. J. Ralph and T. D. Rich, editors. Bird conservation implementation and integration in the Americas: Proceedings of the Third International Partners in Flight Conference (March 2002). United States Forest Service, Asilomar, California, USA. Available online at: URL: http://www.fs.fed.us/psw/ publications/documents/psw gtr191/Asilomar/ pdfs/754-761.pdf.

MacKenzie, D. I., J. D. Nichols, J. E. Hines, M. G. Knutson, and A. B. Franklin. 2003. Estimating site occupancy, colonization, and local extinction when a species is detected imperfectly. Ecology 84:2200-2207.

Niven, D. K., J. R. Sauer, G. S. Bucher, and W. A. Link. 2004. Christmas Bird Count provides insights into population change in land birds that breed in the boreal forest. American Birds 58:10-20. 
Patterson, L.A., W. R. Koski, and C. E. Tull. 1977. Ground surveys of terrestrial breeding bird populations along the Cross Delta Gas pipeline route, Yukon Territory and Northwest Territories, June and July, 1975. Chapter 4 in W. W. H. Gunn, C. E. Tull, and T. D. Wright, editors. Ornithological studies conducted in the area of the proposed gas pipeline route: northern Alberta, Northwest Territories, Yukon Territory and Alaska, 1975. Arctic Gas Biological Report Series Volume 35. Prepared by L.G.L. Limited, Environmental Research Associates, Edmonton, Alberta, Canada.

Sauer, J. R., J. E. Hines, and J. Fallon. 2005. The North American Breeding Bird Survey, Results and Analysis 1966-2005. Version 6.2. 2006. USGS Patuxent Wildlife Research Center, Laurel, Maryland, USA. Available online at: URL: http://w ww.mbr-pwrc.usgs.gov/bbs/bbs.html.

Salter, R., and R. A. Davis. 1974. Surveys of terrestrial bird populations in Alaska, Yukon Territory, Northwest Territories and northern Alberta, May, June, July, 1972. Chapter 2 in W. W. H. Gunn and J. A. Livingston, editors. Bird distribution and populations ascertained through ground survey techniques, 1972. Arctic Gas Biological Report Series Volume 12. Prepared by L.G.L. Limited, Environmental Research Associates, Edmonton, Alberta, Canada.

Schweinsburg, R. E. 1974. An ornithological study of proposed gas pipeline routes in Alaska, Yukon Territory and the Northwest Territories, 1971. Arctic Gas Biological Report Series Volume 10. Prepared by L.G.L. Limited, Environmental Research Associates, Edmonton, Alberta, Canada.

Thomson, W. L. 2002. Towards reliable bird surveys: accounting for individuals present but not detected. Auk 119:18-25.

Tull, C. E., I. D. Thompson, and P. E. Taylor. 1974. Continuing surveys of terrestrial bird populations in Northwest Territories, Yukon Territory, and Alaska: June and July, 1973. Chapter 3 in W. W. H. Gunn, W. J. Richardson, R. E. Schewiensburg, and T. D. Wright, editors. Studies on terrestrial bird populations, moulting sea ducks and bird productivity in the western Arctic, 1973. Arctic Gas Biological Report Series Volume 29. Prepared by L.G.L. Limited, Environmental Research Associates, Edmonton, Alberta, Canada.
Ward, J. 1975. Continuing surveys of terrestrial bird populations in the Mackenzie Valley, June, 1974. Chapter 4 in W. W. H. Gunn, W. J. Richardson, C. E. Tull, and T. D. Wright, editors. Ornithological studies conducted in the area of the proposed gas pipeline route: Northwest Territories, Yukon Territory and Alaska, 1974. Arctic Gas Biological Report Series Volume 30. Prepared by L.G.L. Limited, Environmental Research Associates, Edmonton, Alberta, Canada.

Wiseley, A. N., and C. E. Tull. 1977. Ground surveys of terrestrial breeding bird populations along the Fort Simpson realignment of the proposed arctic gas pipeline route, Alberta and Northwest Territories, June, 1975. Chapter 6 in W. W. H. Gunn, C. E. Tull, and T. D. Wright, editors. Ornithological studies conducted in the area of the proposed gas pipeline route: Northern Alberta, Northwest Territories, Yukon Territory and Alaska, 1975. Arctic Gas Biological Report Series Volume 35. Prepared by L.G.L. Limited, Environmental Research Associates, Edmonton, Alberta, Canada. 